\title{
Social Evolution as Moral Truth Tracking in Natural Law
}

\author{
Filipe Nobre Faria ${ }^{1}$ and André Santos Campos ${ }^{2}$
}

2021

Forthcoming at Politics and the Life Sciences (Cambridge University Press)

\begin{abstract}
Morality can be adaptive or maladaptive. From this fact come polarising disputes on the meta-ethical status of moral adaptation. The realist tracking account of morality claims that it is possible to track objective moral truths and that these truths correspond to moral rules that are adaptive. In contrast, evolutionary anti-realism rejects the existence of moral objectivity and thus asserts that adaptive moral rules cannot represent objective moral truths, since those truths do not exist. This article develops a novel evolutionary view of natural law to defend the realist tracking account. It argues that we can identify objective moral truths via cultural group selection and that adaptive moral rules are likely to reflect such truths.
\end{abstract}

Keywords: Natural law, social evolution, cultural group selection, biopolitics, evolutionary ethics.

\footnotetext{
${ }^{1}$ Nova University of Lisbon/IFILNOVA - Email: filipefaria@ fcsh.unl.pt

${ }^{2}$ Nova University of Lisbon/IFILNOVA - Email: andrecampos@ fcsh.unl.pt
} 
In evolutionary ethics, morality comprises a set of rules that can lead people to proliferate or to be selected out of the evolutionary system. Such rules determine the rightness or wrongness of actions. In this light, the right actions may correspond to the enhancement of fitness, that is, to reproductive success. If so, the right conduct translates into the genetic perpetuation of the addressees of moral regulations. Naturally, different moral rules or principles of cooperation produce distinct evolutionary outcomes. Given that adaptiveness to change dictates the difference between reproductive success and failure, some conceptions of rightness and goodness promote adaptiveness, while others do not. Moralities and cultures can thus be adaptive or maladaptive, depending on whether their moral rules help individuals and social groups to adapt to their environments and increase reproductive fitness. ${ }^{3}$

From this naturalist understanding come sharp disagreements over the metaethical status of moral adaptation. The realist tracking account of morality postulates that it is possible to uncover objective moral truths - or moral facts - and that these truths translate into moral rules that promote genetic survival (James, 2011, pp. 199-203; Richards, 2017). By contrast, evolutionary anti-realism denies the existence of moral objectivity. The most notable anti-realists claim that adaptive moral reasoning evolved to promote cooperation and reproduction, not to track objective truth. They assert that moral reasoning is grounded in contingent preferences, rather than in an open-ended capacity to track or learn about moral facts. For them, moral preferences reflect the unique evolutionary history of the species, not objective moral truths (Joyce, 2006; Ruse \& Wilson, 1986; Street, 2006).

A proper, but unexplored, way to defend the realist tracking account is via the natural law tradition, for natural law holds that we can derive objective and true moral rules from the rational study of nature. The main Darwinian account of natural law is the inclinations account, which depicts true moral rules or virtues as both adaptive and grounded in universal human inclinations (Arnhart, 2001; C. Boyd, 2004; Pope, 1994). But this depiction seems incompatible with evolution because it assumes a unified and stable human nature comprised of unchanging preferences. To uphold the realist tracking account, this article develops a distinct evolutionary view of natural law. It regards

\footnotetext{
${ }^{3}$ Moralities and cultures can also be partly non-adaptive, as certain moral or cultural traits may remain in a population despite not having clear adaptive or maladaptive consequences. This article emphasises the dualism of adaptiveness/maladaptiveness because of its relevance in evolutionary ethics, especially in the context of natural law, where the relevant elements of moral systems are often explained in normative terms.
} 
Aristotelian/Thomistic natural law as (i) group-centred, (ii) detectable by reason, and (iii) objective with variable content. On this basis, the article argues that reason can track adaptive moral rules through cultural group selection, and that these rules are likely to represent objective moral truths.

The article is structured as follows. The first section outlines the main tensions between evolutionary realism and anti-realism. Section two rebuts the anti-realist idea that moral reasoning is based on contingent preferences and defends instead the existence of an open-ended capacity to track moral facts. In turn, it advances a novel evolutionary view of natural law. The last section depicts the workings of moral truth tracking, showing how the limits of moral reasoning are the limits of adaptiveness. In doing so, it tackles the intuitive objection that some adaptive behaviours are wrong according to common moral views. In the end, it should be clear that natural law theory provides conceptual mechanisms for identifying objective moral truths in social evolution. And, by showing that natural law is a viable alternative to evolutionary anti-realism, the article opens a promising avenue for moral realists to explore and further develop.

\section{The moral value of adaptiveness and the evolutionary value of morality}

Philosophers often hold that to be moral is to act according to rules, norms or virtues, whose inherent definition of the good may or may not promote reproductive success. But "the dominant view among evolutionary anthropologists is that morality is a social technology that evolved via biological and cultural selection to deal with problems that early humans faced" (Buchanan \& Powell, 2018, p. 77). Solving these problems allowed individuals and groups to perpetuate. From a functionalist standpoint, morality evolved to enhance fitness, and its technological function is to produce cooperative behaviours that are adaptive (Kitcher, 2011). Such a standpoint seems to be approaching a consensus in evolutionary ethics (Smyth, 2016).

Given this, the meta-ethical meaning of adaptiveness is now a key subject of discussion that leads to conflicting stances, especially when ethicists evaluate the objective truth of moral systems. As an example, imagine that a person follows the moral rules of his or her group, and yet such rules fail to promote the group's survival, including his or her own survival. That person might be following false - and wrongful - moral rules. According to the realist tracking account, this is indeed the case, but anti-realism 
disagrees. The realist ties up objective goodness with adaptiveness, while the anti-realist disconnects them and discards moral objectivity. By doing so, the anti-realist deems it illogical to infer that moral rules are false or wrong when they hinder reproductive fitness.

The realist tracking account defends the existence of an evolutionary kind of objective morality. It holds that moral facts are properties of the world that have normative force because they increase the reproductive fitness of those who can detect them and use them as moral rules. In this regard, moral facts exist independently of contingent preferences or opinions, in the same way that five plus five is always ten regardless of one's stance. The tracking account maintains that the mind has evolved to identify truths about the world, making it possible for people to cognitively track down adaptive notions of the good that are objective (James, 2011, pp. 199-203; Richards, 2017).

Anti-realism offers another understanding of how moral elements fit into evolutionary theory. Here, some authors argue that evolution disproves the existence of objectivity in ethics and that the common belief in moral objectivity is an error, a mere illusion (Joyce, 2006; Ruse \& Wilson, 1986). Morality is then a false belief that had (by chance) adaptive qualities in the past, but is ultimately "a collective illusion foisted upon us by our genes" (Ruse, 1998, p. 253). It is at best a useful fiction (Joyce, 2001, Chaps. VII-VIII). According to this anti-realist view, moral facts cannot be tracked down by reason given that there are no moral values that "bind people irrespective of their desires or interests" (Joyce, 2006, p. 192). As Michael Ruse and E.O. Wilson (1986) explain, the instincts to cooperate are reflected in epistemic rules that became innate. That is, although these instincts make individuals behave in ways that seem moral, they are entirely subjective and derivative of diverse innate preferences.

For Ruse and Wilson, moral rules are the idiosyncratic results of the genetic history of our species. If the species had evolved differently, our rules of conduct would have as well. To illustrate this idea, such authors assert that an intelligent alien species could have evolved to consider cannibalism, incest, or the mutual eating of faeces to be moral. They note that we could have been that species, but, because we have another evolutionary record, we value different rules. In this light, our moral rules are an expression of - naturally selected - personal inclinations or preferences, such as the preference for salt over sugar. Hence, there is nothing objective about moral values given that they $(i)$ originate in human preferences and (ii) are not necessary facts of nature. 
Sharon Street (2006) also argues against the existence of objective morality. ${ }^{4}$ In particular, she finds the realist tracking account implausible and offers an alternative view known as the adaptive link account. Street claims that our minds were naturally selected to link specific behaviours and contexts with fitness maximisation. But she believes that this linkage has little to do with truth tracking and with the existence of objective (mindindependent) moral principles. Rather, we instinctively fear abandonment or search for sex because these behaviours led our ancestors to reproductive success, not because they are moral facts about the world. Our evaluative tendencies represent "adaptive links between our ancestors' circumstances and their responses to those circumstances" (Street, 2006, p. 127), getting people to believe and act in certain ways. She considers that her adaptive link account is more parsimonious, since it links beliefs about morality with reproductive success without assuming that reason evolved to track adaptive moral properties.

Much like Ruse and Wilson, Street reduces morality to naturally selected instincts, to innate contingent desires, which are ultimately a "reflex mechanism" (Street, 2006, p. 127). An example of this mechanism is the automatic reflex that causes a Venus flytrap to snap shut on a fly. Street notes, though, that reflex mechanisms and moral judgements are different. Unlike reflexes, moral judgements involve the formation of reasons, and people possess complex deliberative skills. Yet, the way people respond to reasons is still a reflex mechanism that is linked to biological adaptation. For Street, "we are more sophisticated than Venus fly-traps ... but we're subject to the same evolutionary forces" (James, 2011, p. 184).

Street argues that a general capacity to identify factual truths is of "no advantage or even a disadvantage" (Street, 2006, p. 130) because such a capacity would be too costly for an organism to maintain. A mechanism that links behaviour in certain contexts with reproductive success would suffice. An open-ended capacity for tracking factual truths is then, in her view, unlikely to evolve at all. For Street, it is important to repudiate the existence of an open-ended capacity to make evaluations in several spheres because, if we do have such a capacity, then it shows "that an evolutionary adaptation is not likely to be distorting our truth judgements and ... that evaluations might be more than

\footnotetext{
${ }^{4}$ Street is a moral constructivist. And there is disagreement about whether constructivism is an alternative view to realism and anti-realism. Yet, Street rejects the existence of mind-independent moral truths. Thus, as the realism depicted here entails mind-independence, she remains in the anti-realist camp.
} 
contingent preferences, might be revelatory of facts in the world" (Richards, 2017, p. 153).

However, it is possible to conceive of rules in terms of people's innate desires while upholding moral objectivity. For instance, the inclinations account of natural law - which draws on Aquinas and Darwin - holds that natural law is rooted in the innate propensities of human beings as rational animals. Such beings use their deliberative capacity to formulate objective moral principles that help them to satisfy their natural inclinations. This view regards morality as an expression of propensities that arise from the common biological nature of humans - propensities such as self-preservation, propagation, sociability or knowledge. And by studying biological leanings, rational beings can understand normativity (Arnhart, 2001; C. Boyd, 2004; Pope, 1994). From this standpoint, natural law is objective, but only insofar as it is grounded in particular inclinations that are common to all humans. What this law prescribes is universal and guarantees adaptiveness because it directs people to achieve what they are already prone to in the first place. Still, as we shall see, the inclinations account appears inadequate to defend moral realism.

\section{Reason as an instrument for moral truth tracking}

A robust defence of the realist tracking account in the context of natural law must overcome two challenges. First, it needs to account for the evolution of an open-ended cognitive capacity to track truth, especially moral truth. By doing so, it can show that personal evaluations may not reflect contingent preferences - as anti-realists claim - but facts of the world. Second, it must provide a better account of natural law than the inclinations account, for biocultural diversity and evolutionary change are difficult to explain if natural laws rely on fixed preferences that are common to all humans - as the inclinations account asserts. This article defends moral truth tracking within natural law in a way that is not inherently sceptical or subject-grounded. Let us begin with the antirealist challenge and then move towards the new evolutionary account of natural law. 
2.1. From the adaptive link account to the Darwin Machines

\section{Cultural evolution and the mind}

For Ruse, Wilson and Street, morality relies on the innate and reflexive instincts acquired by our ancestors. Such an idea fits well with the postulates of standard evolutionary psychology (Buss, 1999; Cosmides \& Tooby, 2001). This school holds that people's behavioural traits reflect universal cognitive modules that evolved to solve specific problems in the ancestral past. In this sense, the mind is not a general-purpose organ primarily shaped by culture. Instead, social groups show distinct cultures because those groups have the same specialised cognitive modules, which are responding to different environments - a process known as evoked culture. For example, evo-psychologists often suggest that status competition among males is a universal - and adaptive - innate trait (Buss \& Schmitt, 2017). And this trait only expresses itself differently in populations because it responds to different ecological challenges. This school, however, does not deny the existence of learning capacities or of some phenotypic plasticity. Indeed, it thinks of these features as adaptations. But it mostly stresses specialised cognitive modules and their environmental triggers, which strengthens the notion of moral behaviour as a reflex mechanism.

Yet, as cultural evolutionists point out (Mesoudi, 2009; Norenzayan, 2006), this explanation does not properly account for the importance of the transmitted culture that individuals receive from their social groups. In particular, it does not have a satisfying justification for why environments have changed radically since the ancestral environment. It simply accepts that circumstances have changed and that the same cognitive modules have reacted to the change. And by assuming a universal human nature, it underplays the role of culture in shaping genetic traits, including cognitive modules. But above all, the evolutionary psychology explanation seems to exclude the possibility of learning, identifying, and producing culture and morality as an open-ended process, and as a critical driver of evolution (D. S. Wilson, 2002, p. 29). ${ }^{5}$

As evidence shows (R. Boyd \& Richerson, 2005; Perreault, 2012), cultural and moral evolution occurs at a much faster pace than genetic evolution. The main reason for this occurrence is that genetic evolution is only transmitted vertically, from parents to

\footnotetext{
5 "Culture" here refers to information that is socially transmitted, like language, rituals or inventions (R. Boyd \& Richerson, 2005, p. 5), while "morality" refers to the normative dimension of culture.
} 
offspring. But cultural evolution is not only transmitted vertically. It is also transmitted obliquely, from non-parents of former generations to new generations, and horizontally, from social contemporaries to other contemporaries (Creanza, Kolodny, \& Feldman, 2017, p. 7783). Since culture and morality evolve much faster than genes, the view of morality as a sophisticated "reflex mechanism" (Street, 2006, p. 127) seems implausible. If morality were a reflex mechanism, one would expect the pace of moral change to be tied more to the pace of changes in specialised cognitive modules than it actually is. And moral rules also evolve fast without substantial changes in the environment (Bell, Richerson, \& McElreath, 2009). As such, morality cannot simply react to environmental cues. Rather, it shapes biological evolution, in part via deliberate innovation.

Empirical evidence on tribal interaction reveals the importance of deliberate cultural innovation in the evolutionary system. For instance, two neighbouring African tribes, such as the Nuer and Dinka, that were genetically similar and that shared identical environments, varied considerably in cultural and moral terms. The cultural and moral differences between these tribes had a decisive impact on their reproductive fitness. Namely, "differences in marriage institutions ... led to the Nuer raising larger fighting forces and the expansion of the Nuer at the expense of the Dinka" (Bell et al., 2009, p. 17673). Even with similar genetic constitutions, neighbouring groups can produce distinct moralities and cultures through sheer innovation. This suggests that individuals evolved the capacity to learn, to develop and to generate culture and morality as an open-ended process (D. S. Wilson, 2002, p. 30).

David Sloan Wilson et al. (2014) provide a more comprehensive explanation for how the mind works regarding change in cultural evolution. They understand the mind's capacity to generate cultures and moralities as something analogous to the immune system. Namely, they see the mind as a Darwin Machine, which is a genetic mechanism capable of generating novel adaptive solutions, and that contains an evolutionary process within its constitution (Plotkin, 1994).

Notably, the vertebrate immune system has both innate and adaptive components. The innate component is modular and comprises specialised modules that automatically respond to and fight against disease organisms. This modular component is a reflex mechanism that responds to threats, just as specialised cognitive modules respond to environmental challenges. But because disease organisms can change and appear in unprecedented ways, the immune system has evolved an adaptive component that generates new antibodies to deal with unforeseen threats. When newly created antibodies 
succeed at matching a new disease organism, the adaptive part of the immune system signals its innate part to attack the threat. As Wilson explains, "the immune system is an open-ended process of blind variation and selective retention" and is "therefore capable of providing new solutions to new problems". In a thriving immune system, "antibodies that match antigens reproduce more, not by chance, but because the immune system has been constructed that way" (D. S. Wilson, 2002, pp. 30-31).

As a Darwin Machine, the mind has both specialised mechanisms (e.g. sexual drives, fear of abandonment) and open-ended capacities (i.e. abstract reasoning). Respectively, it has an innate modular component to tackle familiar problems and an adaptive component that generates novel solutions to unknown troubles (D. S. Wilson et al., 2014). When the mind produces novel solutions to environmental obstacles, these solutions tend to replicate more within society - a process that resembles the immune system when tackling new disease organisms. By finding these solutions, the mind discovers new behavioural rules that help individuals and groups to overcome constant challenges, such as out-group competition, scarcity of resources or cooperation failures.

This comprehensive understanding of the mind can explain why people evolved the ability to create new moralities and cultures faster than genetic evolution would permit. That ability "allows us to evolve over short time scales, which are normally accessible only to short-lived species, while at the same time allowing for us to enjoy the benefits of having a long life history" (Perreault, 2012). In other words, it allows us to endure. The open-ended mind arose because our ancestors had to adapt quickly to diverse environments in time and space, as well as to unstable climatic contexts (R. Boyd \& Richerson, 2008). While many animals required genetic adaptations such as growing fur to be protected from the cold, humans could simply create cultural and behavioural norms to solve the problem (e.g. wearing clothes). With open-ended mental capacities, individuals could identify the most appropriate rules for any context and induce collective behavioural change if those rules somehow hindered group fitness. These open-ended capacities can even override particular innate tendencies, such as when humans eat herbs that are repulsive or taste bitter due to understanding their medical benefits (R. Boyd \& Richerson, 2005, p. 11). 


\section{Open-ended reasoning, not a linking process}

The account of moral reasoning as a Darwin Machine - and thus as a tracking device seems more plausible than the anti-realist account of morality as an expression of evolved, contingent desires. In particular, it seems implausible that people merely repeat the adaptive actions of their ancestors in novel contexts, even if via sophisticated reasoning - as Street's adaptive link account suggests. If groups can track adaptive rules to radically transform their behaviours, they may adapt to new contexts without discarding large parts of their genetic constitution - i.e. without reducing fitness. Conversely, groups that depend on the evolution of genetic traits to adapt to new contexts face constant mismatches between past and novel environments, often leading to maladaptation. A ruletracking strategy has more adaptive potential than a strategy that depends on the slower evolution of fitness-enhancing evaluative tendencies. As Joe Henrich (2016) notes, cultural plasticity is the reason behind our success.

The open-ended capacity to track rules is thus more than an expression of contingent desires; it may reveal constitutive facts about the world. The anti-realist rejection of moral facts assumes that facts stand ontologically separated from individuals as independent bodies and that any evolved trait is epistemically directed to survival only (Richards, 2017, p. 154). Yet, if the mind can produce novel solutions to unprecedented problems by examining different ecologies, then it does not merely aim at survival but also at truth about the world. By seeking to comprehend the distinctive features of natural contexts, the mind helps organisms to overcome new ecological challenges, and thus confers fitness benefits to individuals and groups. Likewise, via cultural group selection (R. Boyd \& Richerson, 2005; Henrich, 2016), those groups holding moral rules that foster collective cohesion are more likely to overcome natural obstacles. There is a correspondence between truths about the world - including true statements about ecological conditions - and the normative patterns that promote adaptiveness. Groups that use truths about the world for their survival and that track them more efficiently will have evolutionary advantages in the process of inter-group competition.

However, given the difficulty of acquiring complete and direct knowledge of nature, individuals construct models of reality, which can vary in truth value. People use these models to reason about reality, often through narratives or myths, thus building normative orders. As Jean Porter (2005, p. 19) points out, objective standards of morality are "underdetermined" by human action in social practices and conventions. That is, 
current social practices do not fully correspond to specific moral truths. But those practices can be in accord with or contrary to such truths. Moreover, biological evolution selects upon practices and behaviours, and not directly upon theories or reasons. Practice has priority over theory. Theories or reasons may be wrong, but if they increase fitness, they spread via culture as if they were true. This happens when groups create myths or hold false beliefs that cause adaptive behaviours by chance.

Behaviours based on false reasoning and false beliefs can also be adaptive, even when performed for the wrong reasons (Rappaport, 1979, pp. 97-145). For example, a community may believe in a god that tells people to multiply, which is likely adaptive. Although such a god may not exist, there is still adaptive truth in this belief. Yet, contexts change, and if the community stops believing in that god, it may stop believing in the moral duty to multiply, which can be maladaptive. It might then be preferable for a social group to uphold the true principle contained in the false belief rather than the false belief. Overall, it is likely that false beliefs become inadequate when environmental changes take place, which shows the importance of grasping and tracking moral facts in social evolution.

The anti-realist may argue that the existence of the mind as a flexible trackingdevice does not show that moral facts exist. Adaptiveness and moral truth are different things, after all, and one cannot simply go from fact to value. To do so is to commit the naturalistic fallacy. From this standpoint, moral reasoning can track adaptive rules but not true moral rules. Anti-realists, though, tend to overlook the (Aristotelian) moral functionalism of adaptive rules. In this setting, to know if something is good is to ask for its natural function. If a living being's function is to grow and multiply, to do so is objectively good. Likewise, if the function of moral rules is to promote adaptiveness, the rules that do so are objectively good. The naturalistic fallacy is then bypassed. ${ }^{6}$ Moreover, "there are objective facts about the conditions and patterns of interaction that make cooperation profitable" (Fraser \& Sterelny, 2017, p. 985). Elinor Ostrom (1998), for instance, identified general rules that help communities to solve collective action problems. And evolutionary game theory can reveal the best cooperation strategies in different situations. If rules have the function of enhancing adaptive cooperation, we have cause to think that adaptive rules are indeed true, for we can identify them, allowing the moral functionalist to understand their concrete functions and, hence, their truthfulness.

\footnotetext{
${ }^{6}$ For further Neo-Aristotelian arguments against the naturalistic fallacy objection, see the works of William Casebeer (2003), Philippa Foot (2001) and Judith Thomson (2008).
} 
2.2. Natural Law Ethics and the Aristotelian-Thomistic Synthesis

\section{Discarding the Universalistic View of Natural Law}

To uphold moral truth tracking in natural law, one must first clarify the interpretation problems of the standard Darwinian account of natural law: the inclinations account. Attributed to such authors as Craig Boyd (2004), Stephen J. Pope (1994) and, especially, Larry Arnhart $(1998,2001)$, this account regards natural law as consonant with evolutionary ethics and rooted in the biological features of human agents. It depicts the moral good as adaptive, objective, and grounded in human inclinations or preferences. It sees natural law as a universalistic set of virtues or rational principles - and it is in this light alone that their proponents think about social evolution.

The inclinations account, which includes Darwinian interpretations of Aquinas' natural law (Arnhart, 1998, 2001), expresses a classical universalistic view of natural law. The universalistic view presupposes a universal human nature and regards natural law as rooted in the natural instincts of rational human beings - morality is then an expression of common human propensities, which science can understand. As such, the contents of natural law are immutable in time and space, in part because human nature and its inclinations are unchangeable. This view is typical of the Stoic version of natural law, according to which people's sense of belonging - oikeosis - expands from the self to other living creatures, and, with the aid of reason, even to all of humanity in the kosmopolis. In the words of Cicero, "[t]here will not be one law at Rome and another at Athens, one now and another later; but all nations at all times will be bound by this one and eternal and unchangeable law" (Cicero, 1999, p. 71). Such a view is influential in the modern era, for it fits best into the compositive-resolutive method of scientific knowledge whereby individuals, rather than groups, are the point of departure when one considers any kind of normativity.

By taking this universalistic view, the inclinations account seems incompatible with evolutionary ethics, since it validates natural law only if human nature is adaptive to change but not itself susceptible to change. Yet, in evolution, we should expect constant change. This account also makes it difficult to understand how different cultures can develop distinct and successful evolutionary strategies, as it considers that any culture, regardless of circumstances, should follow the same moral rules, the rules that are adaptive and thus right. Some evolutionary anti-realists take this universalistic standpoint 
to be representative of natural law. So they sensibly regard evolutionary ethics and natural law as incompatible (Ruse, 2001; E. O. Wilson, 1978).

\section{Upholding Natural Law with Variable Content: Aristotle}

Another classical view of natural law, however, overcomes these challenges. It is the view of natural law with variable content, which is compatible with evolution and has not yet been explored by evolutionary theorists. Here, natural law is universal only in the sense that it applies everywhere, but it can express itself differently in every context. This alternative view asserts that human nature has deep biological grounds, but those grounds are already in play inside the system of natural law. The system creates biological natures or propensities, rather than the reverse. To understand morality, rational beings must study the laws of nature and the different ways that these laws express themselves, which leaves room for change in the normative contents of natural law. Natural law with variable content can be found mostly in Aristotle, but Aquinas should also be interpreted in this light.

When approaching natural law, Aristotle is thinking of humans as rational and social animals. Rational animals can understand the world and deliberate about certain courses of action by using deductive and inductive reasoning. Social animals depend on their rational dimension because the rationality inherent in the deliberation practices concerning the good requires the prior formation of the polis. But rational animals also depend on their social dimension, since communities precede individuals logically and chronologically (Aristotle, 1998, I, 1253a9-29). Only in political communities can men be truly rational.

The social setting of Aristotelian natural law, then, involves rationality and is group-centred. And if group norms are partly conventional and parochial (Aristotle, 2000, V 10, 1134b18-19), they are also partly required by people's rational capacity. Aristotle endorses neither pure conventionalism, the Sophistic view that social conventions are valid simply because they are accepted in a group, nor pure naturalism, the view that there are universal principles of goodness applicable to all times and places (Burns, 2011, p. 167). For him, the conventionalist view deprives existing social orders of the proper justifications that practical reasoning can bring. And the pure naturalist view is too rationalistic and inflexible, since it relies on a standard that is supposedly superior to the laws and customs of particular societies. 
However, Aristotle sometimes seems to invoke a universalist framework. For instance, he maintains that natural law has the same force or power (dynamis) everywhere (Aristotle, 2000, V, 1113b19). What can this mean? He defines power as "a principle of change in another or in itself as another" (Aristotle, 1995a, V, 13, 1020a1-2; IX, 1, 1146a10-11). That is, power can produce change in different directions. Medicine, which qualifies as an example of power, may act to give health or accidentally to deprive of health. The principle of change behind warming another person to lower her fever and give her health is the same principle that deprives a person of health if the act of warming her is omitted (Aristotle, 1995a, VII, 7, 1032b18-21). As such, the power to do good can be actualised in the action of doing or not doing the required good (Aristotle, 1995a, IX, $2,1046 \mathrm{~b} 24-28)$.

The same occurs with natural law: it can be actualised or not, that is, specific laws can be rational or irrational in this sense. Such is the range of Aristotle's claim that natural law has the same force or power everywhere, just as fire burns equally in Greece and in Persia, even though the conventional norms are different in Greece and Persia. Each culture has its way of valuing things, of attributing specific contents to values, and of creating binding conventions. And cultures value things following the natural faculties by which their members are inclined towards a good. However, those norms can be rational or irrational depending on whether they are in accordance with principles of practical rationality that, like mathematics, are equally valid everywhere. So, some laws are irrational, and some are rational; that is, they are against or in accordance with natural law.

Aristotle's primary example is political constitutions. He says that human-made laws are not the same everywhere, just as constitutions are not the same, but everywhere only one constitution is by nature the best (Aristotle, 2000, V, 10, 1135a3-5). Yet, he is not saying that there is one single optimal constitution that applies equally to every culture - as Stoic views of natural law could say. What he is saying is that, in every culture, there is an optimal constitution for that specific culture. It is not only conventional laws that have different contents; natural law also has variable content, provided that it is rational within each particular state of affairs. 


\section{Upholding Natural Law with Variable Content: Aquinas}

This Aristotelian framework fits into Aquinas' broader theory of laws. For Aquinas, natural law derives from eternal law and is actualised by human laws. In themselves, natural laws are self-evident rational principles, without any practical relevance. Natural laws must then be understood as expressions of eternal laws, which determine how rational entities partake in a cosmos with other entities and thus share certain features with them (Aquinas, 1980, II-I q. 91 a. 2). But natural laws also relate to human laws directly. Human laws turn the general principles of natural law into actual rules, that is, into conventional laws. And these rules are addressed to human agents as rational animals in Aristotle's sense (Aquinas, 1980, II-I q. 94 a. 2).

The fact that natural law is in-between two different sets of laws - eternal and human - is vital to understanding what Aquinas is saying. Unlike what authors such as Arnhart $(1998,2001)$ claim, natural law cannot be rooted in human nature's inclinations, given that these inclinations follow from the context of eternal laws. For Aquinas, people's natural inclinations must be satisfied at three levels for the fullest flourishing of human life: the natural tendencies of the body; the natural tendencies of sensory desires; and the natural tendencies of intellectual desires (Aquinas, 1980, I-II q. 94 a. 2). These tendencies show that there is a continuity between human beings and other animals. This continuity seems compatible with the Darwinian thesis that humans evolved from nonhuman animals (Barad, 1995). But it is a mistake to think that Aquinas' theory provides a sufficient basis for claiming that natural law is rooted in a "biological paradigm" (Arnhart, 2001; Lisska, 1996, pp. 96-109). The reason is that all natural things, including irrational creatures, are subject to eternal laws insofar as their essences embody the principles that determine their rightful actions (Aquinas, 1980, I-II q. 93 a. 5). According to Aquinas, men have certain propensities because God created them as such within the realm of eternal laws. And natural laws are the instruments whereby people access eternal laws via understanding. Human inclinations develop inside a framework that already includes natural laws, so inclinations cannot produce such laws.

Aquinas (1980, II-I q. 95 a. 2) also states that there are two ways to derive human laws from natural law. One way is to derive conclusions from first principles (per modum conclusionis), for example, to derive "one must not kill" from "one must hurt nobody". Another way is to make a specific application of a general and undetermined law (per modum determinationis). In the latter way, human laws add certain contents to natural 
law (Finnis, 1998, pp. 266-270), and this addition allows human laws to attribute variable contents to natural laws.

For instance, suppose there is a natural law indicating that people ought to have freedom of mobility. If so, there should be human laws facilitating that goal, and people should be free, for example, to drive to their desired destinations. But whether it is obligatory to drive on the right side or the left side of the road is something that is only specified by human laws when applying natural law. The obligation to drive on a given side of the road is not deduced from the first principles of natural law, but from the authority of human enactment.

When natural laws appear in a general and undetermined form, they only become binding the moment they are posited and actualised by human enactment. This is the moment when rational beings create human laws that induce their addressees to act in a certain way, thus bringing moral obligation into the world. Human laws command what, in the absence of convention, is morally optional and uncertain. And they allow natural law to have variable content from time to time and place to place (Aquinas, 1980, II-I q. 94 a. 5; Green, 2014, pp. 204-205).

This reading of natural law and practical rationality provides the basic framework for thinking about morality as both natural and group-centred. In such an Aristotelian/Thomistic framework, moral rules can be objective without having to be universally immutable. Their contents can change from culture to culture, and from time to time, and yet remain an expression of natural law. Also, this account of natural law is functionalist and teleological. It draws on prominent functionalist explanations in evolutionary ethics (Smyth, 2016), especially on group selection (Sober \& Wilson, 1998), for each social group produces different evolutionary strategies that reflect its context and specific traits. From a natural law standpoint, the telos of the social group and its members is sustainability and perpetuation over time - the common good, in Aquinas' terminology. And the role of reason concerning moral virtue is to understand how to reach selfactualisation. The Aristotelian good life, then, means functional adaptiveness, and the search for the good communal life may represent the search for group adaptiveness in the face of inter-group competition. 


\section{Towards moral truth tracking}

The remainder of this article explains the workings of moral truth tracking in natural law. It clarifies how rational minds may evaluate and identify adaptive moral rules that reflect objective standards of morality. In this sense, if moral facts were different, rational minds would relate to morality differently. Reason is unlikely to be a sophisticated slave of evolved passions or instincts - as the Humean tradition might suggest. Rather, reason is better understood as a largely instinct-independent tool, insofar as it can track and apply adaptive behavioural rules.

\subsection{The limits of reason in truth tracking}

To be apt to reason in favour of reproductive fitness does not mean one will necessarily do so, or that reasoning that is contrary to fitness enhancement cannot occur. Some evolutionary thinkers have recognised the human capacity to use reason against the natural telos of genetic reproduction. As Richard Dawkins puts it, "we, that is our brains, are separate and independent enough from our genes to rebel against them... We do so in a small way every time we use contraception" (Dawkins, 2016, p. 434). Daniel Dennett adds that this capacity "is our transcendence, our capacity to rebel against the tyranny of the selfish replicators ... and there is nothing anti-Darwinian or antiscientific about it" (Dennett, 1995, p. 471). But although moral reasoning seems open-ended, it remains bound by the laws of natural selection. In evolutionary natural law, we can reason rightly or wrongly about morality at the epistemic level. But only adaptive rules can be objectively true and represent normative properties of the world. Ultimately, if morality's function is to enhance fitness through cooperation, then to "rebel" against that function is to fall outside of the moral scope.

This view is both empowering and critical of reason. At heart, it confers reason a strong role in understanding morality. Yet, it also shows that reason cannot extend beyond the limits of adaptiveness when postulating true moral principles. For instance, let us assume that in-group favouritism is adaptive (Faria, 2017; Hartshorn, Kaznatcheev, \& Shultz, 2013). One may still prefer another moral strategy such as universal egalitarianism - i.e. treating all groups equally. But if this other moral strategy is maladaptive, it ends up being outperformed (and erased) by more adaptive moralities via cultural group 
selection. In these instances, because moral facts tie up with adaptiveness, universal egalitarianism cannot be true.

One could still argue that moral rules can be true even when they lead their groups to extinction. This claim, however, would disconnect moral truth from the adaptive requirements of evolution - a doubtful premise in evolutionary moral realism. To defend this premise, the evolutionary realist would need to argue that moral reasoning has no adaptive function. Yet, because finding cooperation rules is essential for human survival, such a claim is implausible. Evolutionary ethicists thus tend to dismiss it (Smyth, 2016). Nearly all evolutionary realists connect moral truth to adaptiveness, in part or in whole (Collier \& Stingl, 2013; Fraser \& Sterelny, 2017). When a rule is maladaptive, we have good reason to think it is false.

In this light, the potential and limits of reason look clear. Reason can discover natural laws of adaptiveness, which are also truths about the world, but it cannot transcend them. As natural selection constrains our moral choices, the existing freedom of choice to establish any given set of rules is, in part, an illusion. What authors like Dawkins (2016, p. 434) and Dennett (1995, p. 471) regard as our mental capacity to transcend evolutionary laws - or selfish genes - is mere maladaptation. Because those laws select against maladaptive choices, reason has moral power only within the limits of natural selection.

\subsection{The practice of moral tracking}

The Aristotelian model of natural law illuminates the practice of moral truth tracking in the social and political realm. Aristotle understands an unjust act as an act contrary to the political law of one's polis (Aristotle, 2000, V, 1, 1129b1-25; V, 7, 1134b18), thus suggesting that there is no impartial standard of justice above one's political group. Yet, he notably claims that, by nature and everywhere, the perfect political regime does exist. Although Aristotle defends existing institutions as bearers of moral truths, he leaves room for progress towards an ideal regime. Such progress takes place inside the socio-political group, as different collectives require distinct optimal rules. Socio-political organisation is the product of collective "friendship" (Aristotle, 2000, VIII, 1, 1155a17-33).

Likewise, in social evolution, the group is the natural basis of morality and a potential unit of biocultural selection, for prosocial behaviour is likely to evolve via group selection (Okasha, 2006; Sober \& Wilson, 1998; Turchin, 2016) or/and inclusive fitness 
(Birch, 2017, Chap. II). The majority of social evolutionists endorse these two models, which are equivalent "on the grounds that gene frequency change can be correctly computed using either approach" (Birch \& Okasha, 2014, p. 28).

Notably, a social group consists of interdependent agents - for instance, a family, a nation, or a civilisation. Groups have an identity and a sense of purpose, including rules of cooperation and punishment mechanisms. Sometimes their borders overlap, but they remain identifiable. From a group selection standpoint, adaptive groups are those that successfully use rules and punishment mechanisms to suppress self-serving behaviour. This suppression allows them to compete more ably against other groups (Sober \& Wilson, 1998). A tribe that can suppress factions, and thus increase cooperative cohesion, is more likely to prevail against another tribe where agents only cooperate as small families - i.e. a tribe plagued by familism. By contrast, if competition between tribes is weak, strong familism pays off. Overall, when inter-group competition is weak, individual free-riding prevails, for egoism beats altruism within groups, but groups of altruists beat groups of egoists (D. S. Wilson \& Wilson, 2007).

Also, cultural evolutionists have found important cooperation patterns in successful groups. For instance, according to Boyd and Richerson (2005, p. 13), a few innovators of cultural norms and many conformists typically constitute an adaptive biocultural group. Innovators update the behavioural practices of a group when it faces internal and external threats, while conformists make it a cohesive unit by adhering to new rules. Innovators, in particular, must reason about the epistemic conditions of their ecologies and assess the aptness of cooperation rules - a process that highlights moral reasoning as a vital tool of innovation.

The role of reason in moral truth tracking is then to assess the trade-offs involved in enhancing group reproductive fitness. Yet, we should not conclude that groups increase their fitness by simply warring against non-related others - an idea associated with social Darwinism. A reasoned appraisal of moral truth understands that war does not always pay off. Even though war is a powerful adaptive force of our evolutionary past (Turchin, 2016), its careless use can be harmful, as it can endanger the continuity of groups. War may cause groups to lose their most altruistic members in the battlefields or even lose entire populations. Given this, collectives must find the most appropriate relations with other collectives by assessing the relevant trade-offs.

The same logic applies to the ethics of reproduction. For example, an investment in sheer reproductive quantity may be maladaptive if it represents the expansion of unfit 
characteristics. That is why Darwin understood the common good as rearing "the greatest number of children in full vigour and health, with all their faculties perfect, under the conditions to which they are subjected" (Darwin, 1989, p. 121). Of course, medical technology can now fix many health issues, which allows many people with health problems to adapt to current ecologies. Today, even those with unfit, yet fixable, debilitations would fit into Darwin's notion of the common good. The application of moral rules may hence change along with technological progress.

But perhaps the most crucial trade-off is the one between pursuing group adaptiveness and sustaining the global environment. Inter-group competition may cause environmental damage - for instance, in the case of biological or atomic warfare. And aggressive competition for resources might lead to resource depletion. In this sense, solving ecological threats is a moral necessity, which often requires inter-group cooperation. Yet, natural selection rests upon relative fitness. It is not so relevant that a group survives in absolute terms; what is important is that it keeps growing better than other groups (D. S. Wilson, 2002, p. 38). Even with large-scale environmental cooperation, some groups will enhance their fitness better than others since cultural and moral diversity is enough to cause differences in adaptive capacities. And there are no known intelligent extra-terrestrials to exert pressure for humanity to become a single unit of selection. So, natural selection at the group level will probably continue to operate among human-like communities.

Yet, the size and cultural identity of groups may vary according to ecological changes. In the last 10,000 years, adaptive communities have replaced less adaptive communities, in part because of their superior capacity to learn and process information (Turchin, 2016). This capacity has allowed for collective action to take place at larger scales, giving rise to modern nations constituted by millions. For sure, alliances against common enemies often give rise to new socio-political identities. But there is a trade-off between acting mostly at the small scale and generating collective actions at a larger scale. By default, agents ought to prioritise the smaller scale, where genetic relatedness is higher and where more of their genes can replicate. However, it may be maladaptive to prioritise the smaller scale, since large cohesive groups have competitive advantages over small groups, as size is often a valuable group-level adaptation (D. S. Wilson, 2002, p. 32). When faced with these complexities, agents who best understand nature's trade-offs should be better at finding the most adaptive rules for the appropriate scale. 


\subsection{From the intuitive objection to moral progress}

A sceptic may counterargue that adaptive moral rules do not reflect objective truths because rape or genocide can also be adaptive. Are these acts not clearly immoral, even if they are adaptive? Let us call this critique the intuitive objection. Some evolutionary moral realists dodge this objection by stating that moral facts are only partly connected to adaptiveness. For instance, Collier and Stingl argue that "morality is not a special kind of fitness, though it contributes to fitness" (Collier \& Stingl, 2013, p. 225). By rejecting fitness enhancement as the sole criterion to assess moral facts, these realists can dismiss rape or genocide as a moral good. Indeed, realists may assert that when moral principles are maladaptive, they are untrue, but moral facts do not equate with adaptiveness. In this sense, to be adaptive is a necessary condition for moral rules to be true, yet not a sufficient one. Rape being adaptive, then, would not make it a moral fact. However, at the ultimate level, fitness enhancement seems both necessary and sufficient. For, as E.O. Wilson notes, "morality has no other demonstrable ultimate function" than to perpetuate genes (E. O. Wilson, 1978, p. 167). It is then hard to argue that moral rules such as "commit genocide or rape" are false if they enhance fitness. Functionalist or teleological accounts of the good could then be seen as incompatible with our considered moral judgments of the day (Odenbaugh, 2017).

Yet, the fitness trade-offs in natural law show that cases like rape or genocide do not have to collide with our considered moral judgments. Rape, for instance, is a form of cheating on the sexual and procreative rules of a collective. It may benefit the rapist, but not the group. Groups comprised of many rapists, rather than cooperators, are unlikely to survive under group selection. As such, rape is not a long-run adaptive strategy, which suggests that it is not a moral fact. Moreover, the success rate of insemination in rape acts is notably low - around $2 \%$ (Lloyd, 2001). This also indicates that rape is an ineffectual way to enhance fitness (Odenbaugh, 2017, p. 1042).

But what about mass rape as the result of one group conquering another? Some could argue that this would be an adaptive strategy for any group, thus making it a moral good. Mass rape might be a bad strategy, though. For example, this strategy may create a new identity group, due to mixing two different biocultural identities, and this new group could become an adversary of the conquering group. Of course, to prevent this problem, the conquerors may integrate the members of the new group. But these new members may cause instability by cooperating mostly among themselves. And if they blend with 
the conquering group, they may carry new norms or inclinations, which may change the successful cultural norms that led the conquerors to win conflicts. A better strategy would be not to rape at all and to expand by increasing birth rates, that is, by keeping group integrity and avoiding disruption. The short-term gain strategy of mass rape, as in the case of individual rape, might not be adaptive in the long-run, which casts doubt on it being a moral fact.

Genocide as a strategy for surpassing out-groups also has serious limitations. For instance, it would not be adaptive if humans wiped out most living beings on earth, as that is ecologically unsustainable and would hence lead to human downfall. Likewise, groups may often have more to gain from mutual interdependence than from eliminating one another. Thus, it may be detrimental for groups to embrace a steady moral rule such as "commit genocide". The fact that our considered moral judgments of the day usually see genocide as immoral suggests that it might not be as adaptive as some might think. And people must know something about morality as a social technology since they succeeded in evolution in part because of mastering it. However, we still face an uncomfortable possibility: in some circumstances, actions that we deem unacceptable at a given time may, in fact, be adaptive. Our considered moral judgments, though, are often right in disapproving these actions. And claims about the potential adaptiveness of such actions must show that, in each context, there are no better alternatives - fitness-wise.

Given all the trade-offs in nature, even rational agents require heuristics, as reason cannot always show people how to build adaptive groups. After all, reason may also produce novel moral rules that lead communities to extinction. In this regard, Aristotle's caution seems justified. He holds that scientific scrutiny can discover natural law principles. At the practical level, though, he cherishes socio-political conventions that have already stood the test of time and thus contain some natural law truths. In doing so, Aristotle appeals to practical wisdom (Burns, 2011, pp. 67-68). Indeed, it is hard to know exactly how a group can be adaptive at a practical level. But it is possible to find moral principles that are epistemically valid. For instance, we know that to have ten children is more adaptive than to have zero or that a population with unchanging sub-replacement levels becomes extinct. The Aristotelian project of studying natural regularities and teleology to understand morality remains as relevant as ever. Still, politics differs from science in a vital sense. In politics, "precision is not to be sought for alike in all discussions", and it is enough to postulate truth "roughly and in outline" (Aristotle, 1995b, 1094b12-14; 1104a1-5). 
However, despite the importance of convention, evolutionary natural law also entails moral progress. As models of gene-culture coevolution show (R. Boyd \& Richerson, 2005; Durham, 1991), culture shapes genetic evolution and genes shape culture in a feedback loop. In particular, rules select for the genetic traits that will evolve within groups - a selection that proceeds through systems of punishment and rewards (Witt, 2008). But for moral truth tracking to prevail in a population, moral rules cannot stifle open-ended reasoning when aiming at group conformity. Rules that select against moral innovators can eliminate the capacity for truth tracking, thus hindering epistemic progress. If this capacity disappears, agents lose their neural plasticity and must hence rely on neural specificity, namely, on rigid reflexive instincts.

It may be tempting for any group to increase its fitness by imposing total conformity to plans that work in a given environment. Yet, total conformity may destroy a group's capacity to acquire truths about the world, and groups need this capacity to better adapt to new environments. To be resilient, communities must find the correct point between total conformity to repressive rules and total atomisation, that is, between the absence of innovation and the dissolution of the collective. Communities must find, in fact, Aristotle's golden mean.

Ultimately, if evolution selects for group agents who excel at reasoning about moral changes, then there must be in-built natural forces that select for superior reasoning capacities. The best minds are better apt to prosper since they can best understand the evolutionary structures of the world, which contain moral information that is factual and adaptive. If moral progress reflects an increasing capacity to track moral facts, such progress is not only possible but also an essential feature of natural law. Indeed, we might be just at the beginning of understanding morality, as there could be much more to it than our evolved capacities now grasp. But better moral rules can foster the improvement of reasoning capacities, which should gradually shed light on morality itself.

\section{Conclusion}

This article developed a novel evolutionary view of natural law to defend the realist account of moral truth tracking. It argued that the common anti-realist challenges to moral realism fail within evolutionary ethics. In the absence of a proper Darwinian account of natural law, the article advanced a view of natural law as group-centred, discoverable by 
reason and objective with variable content. On this basis, it argued that reason can track adaptive moral rules via cultural group selection and that such rules are likely to correspond to objective moral truths.

\section{Financial support}

This paper was funded by Fundação para a Ciência e Tecnologia, Norma Transitória Contract D.L. no. 57/ 2016, Grant/Award Number IF/01587/2015.

\section{Bibliography}

Aquinas, T. (1980). Summa Theologiae S. Thomae Aquinatis Opera Omnia (Vol. II). Stuttgart: Friedrich Frommann Verlag.

Aristotle. (1995a). Metaphysics (W. D. Ross, Trans.). In J. Barnes (Ed.), The Complete Works of Aristotle. Princeton, NJ: Princeton University Press.

Aristotle. (1995b). On the Soul (J. A. Smith, Trans.). In J. Barnes (Ed.), The Complete Works of Aristotle. Princeton, NJ: Princeton University Press.

Aristotle. (1998). Politics (D. Reeve, Trans.). Indianapolis: Hackett.

Aristotle. (2000). Nicomachean Ethics. Cambridge: Cambridge University Press.

Arnhart, L. (1998). Darwinian Natural Right: The Biological Ethics of Human Nature. Albany, NY: State University of New York Press.

Arnhart, L. (2001). Thomistic Natural Law as Darwinian Natural Right. In F. D. Miller, E. F. Paul, \& J. Paul (Eds.), Natural Law and Modern Moral Philosophy (pp. 133). Cambridge: Cambridge University Press.

Barad, J. (1995). Aquinas on the Nature and Treatment of Animals. San Francisco: International Scholars Publications.

Bell, A., Richerson, P. J., \& McElreath, R. (2009). Culture Rather Than Genes Provides Greater Scope for the Evolution of Large-Scale Human Prosociality. PNAS, 106(42), 17671-17674.

Birch, J. (2017). The Philosophy of Social Evolution. Oxford: Oxford University Press.

Birch, J., \& Okasha, S. (2014). Kin Selection and its Critics. BioScience, 65(1), 22-32.

Boyd, C. (2004). Thomistic Natural Law and the Limits of Evolutionary Psychology. In P. Clayton \& J. Schloss (Eds.), Evolution and Ethics: Human Morality in 
Biological and Religious Perspective (pp. 221-237). Grand Rapids, MI: William B. Eerdmans Publishing.

Boyd, R., \& Richerson, P. J. (2005). Not by Genes Alone: How Culture Transformed Human Evolution. Chicago: University of Chicago Press.

Boyd, R., \& Richerson, P. J. (2008). Gene-Culture Coevolution and the Evolution of Social Institutions. In C. Engel \& W. Singer (Eds.), Better Than Conscious? Decision Making, the Human Mind, and Implications for Institutions (pp. 305325). Cambridge, MA: MIT Press.

Buchanan, A., \& Powell, R. (2018). The Evolution of Moral Progress: A Biocultural Theory. Oxford: Oxford University Press.

Burns, T. (2011). Aristotle and Natural Law. London: Continuum International Publishing Group.

Buss, D. M. (1999). Evolutionary Psychology: New Science of the Mind. Boston: Allyn and Bacon.

Buss, D. M., \& Schmitt, D. P. (2017). Sexual Strategies Theory. In T. Shackelford \& V. Weekes-Shackelford (Eds.), Encyclopedia of Evolutionary Psychological Science. Cham: Springer International Publishing.

Casebeer, W. (2003). Natural Ethical Facts. Cambridge, MA: MIT Press.

Cicero, M. T. (1999). On the CommonWealth and On the Laws (J. E. G. Zetzel, Trans.). Cambridge: Cambridge University Press.

Collier, J., \& Stingl, M. (2013). Evolutionary Moral Realism. Biological Theory, 7, 218226.

Cosmides, L., \& Tooby, J. (2001). What is Evolutionary Psychology? Explaining the New Science of the Mind. New Haven: Yale University Press.

Creanza, N., Kolodny, O., \& Feldman, M. (2017). Cultural Evolutionary Theory: How Culture Evolves and Why it Matters. PNAS, 114(30), 7782-7789.

Darwin, C. (1989). The Descent of Man. New York: New York University Press.

Dawkins, R. (2016). The Selfish Gene. New York: Oxford University Press.

Dennett, D. C. (1995). Darwin's Dangerous Idea: Evolution and the Meaning of Life. New York Simon \& Schuster.

Durham, W. H. (1991). Coevolution: Genes, Culture and Human Diversity. Stanford: Stanford University Press.

Faria, F. N. (2017). Is Market Liberalism Adaptive? Rethinking F. A. Hayek on Moral Evolution. Journal of Bioeconomics, 19(3), 307-326. 
Finnis, J. (1998). Aquinas: Moral, Political, and Legal Theory. Oxford: Oxford University Press.

Foot, P. (2001). Natural Goodness. Oxford: Clarendon Press.

Fraser, B., \& Sterelny, K. (2017). Evolution and Moral Realism. British Journal for the Philosophy of Science, 68, 981-1006.

Green, B. P. (2014). Transhumanism and Catholic Natural Law: Changing Human Nature and Changing Moral Norms? In C. Mercer \& T. Trothen (Eds.), Religion and Transhumanism: The Unknown Future of Human. Santa Barbara: Praeger.

Hartshorn, M., Kaznatcheev, A., \& Shultz, T. (2013). The Evolutionary Dominance of Ethnocentric Cooperation. Journal of Artificial Societies and Social Simulation, 16(3), 7.

Henrich, J. (2016). The Secret of Our Success. New Jersey: Princeton University Press.

James, S. M. (2011). An Introduction to Evolutionary Ethics. Oxford: Wiley-Blackwell.

Joyce, R. (2001). The Myth of Morality. New York: Cambridge University Press.

Joyce, R. (2006). The Evolution of Morality. Cambridge, MA: MIT Press.

Kitcher, P. (2011). The Ethical Project. Cambridge, Massachusetts: Harvard University Press.

Lisska, A. J. (1996). Aquinas' Theory of Natural Law: An Analytic Reconstruction Oxford: Clarendon Press.

Lloyd, E. A. (2001). Science Gone Astray: Evolution and Rape. Michigan Law Review, 99(6), 1536-1559.

Mesoudi, A. (2009). How Cultural Evolutionary Theory Can Inform Social Psychology and Vice Versa. Psychological Review, 116(4), 929-952.

Norenzayan, A. (2006). Evolution and Transmited Culture. Psychological Inquiry, 1, 123-128.

Odenbaugh, J. (2017). Nothing in Ethics Makes Sense Except in the Light of Evolution? Natural Goodness, Normativity, and Naturalism. Synthese, 194, 1031-1055.

Okasha, S. (2006). Evolution and the Levels of Selection. Oxford: Oxford University Press.

Ostrom, E. (1998). A Behavioral Approach to the Rational Choice Theory of Collective Action. American Political Science Review, 92, 1-22.

Perreault, C. (2012). The Pace of Cultural Evolution. PloS ONE, 7(9). doi:https://doi.org/10.1371/journal.pone.0045150 
Plotkin, H. (1994). Darwin Machines and the Nature of Knowledge. Cambridge, MA: Harvard University Press.

Pope, S. J. (1994). The Evolution of Altruism and the Ordering of Love. Washington, DC: Georgetown University Press.

Porter, J. (2005). Nature as Reason: A Thomistic Theory of the Natural Law. Michigan: William B. Eerdmans Publishing Company.

Rappaport, R. (1979). Ecology, Meaning and Religion. Berkeley: North Atlantic Books. Richards, R. J. (2017). Evolutionary Ethics: A Theory of Moral Realism. In R. J. Richards \& M. Ruse (Eds.), The Cambridge Handbook of Evolutionary Ethics (pp. 143157). Cambridge: Cambridge University Press.

Ruse, M. (1998). Taking Darwin Seriously: A Naturalistic Approach to Philosophy. New York: Prometheus Books.

Ruse, M. (2001). Can a Darwinian be a Christian? The Relationship Between Science and Religion. New York: Cambridge University Press.

Ruse, M., \& Wilson, E. O. (1986). Moral Philosophy as Applied Science. Philosophy, 61(236), 173-192.

Smyth, N. (2016). The Function of Morality. Philosophical Studies, 174, 1127-1144.

Sober, E., \& Wilson, D. S. (1998). Unto Others: The Evolution and Psychology of Unselfish Behavior. Cambridge, Mass.: Harvard University Press.

Street, S. (2006). A Darwinian Dilemma for Realist Theories of Value. Philosophical Studies, 127(1), 109-166.

Thomson, J. J. (2008). Normativity. Chicago: Open Court.

Turchin, P. (2016). Ultrasociety. Chaplin, Connecticut: Beresta Books.

Wilson, D. S. (2002). Darwin's Cathedral. Chicago: University of Chicago Press.

Wilson, D. S., Hayes, S., Biglan, A., \& Embry, D. D. (2014). Evolving the Future: Toward a Science of Intentional Change. Behavioral and Brain Sciences, 37(4), 395-416.

Wilson, D. S., \& Wilson, E. O. (2007). Rethinking the Theoretical Foundation of Sociobiology. The Quarterly Review of Biology, 82(4), 327-348.

Wilson, E. O. (1978). On Human Nature. Cambridge, MA: Harvard University Press.

Witt, U. (2008). Observational Learning, Group Selection, and Societal Evolution. Journal of Institutional Economics, 4(1), 1-24. 